\title{
Fixed point theorems for fuzzy mappings in metric spaces with an application
}

\author{
Jianhua Chen and Xianjiu Huang
}

${ }^{*}$ Correspondence:

xjhuangxwen@163.com

Department of Mathematics,

Nanchang University, Nanchang,

330031, P.R. China

\begin{abstract}
In this paper, we prove some new fixed point theorems for fuzzy mappings under a $G$-distance function and a $G^{\prime}$-distance function in complete metric spaces. Our results extend, generalize, and improve some existing results. Moreover, an example and an application are given here to illustrate the usability of the obtained results.
\end{abstract}

MSC: $47 \mathrm{H} 10 ; 54 \mathrm{H} 25$

Keywords: fixed point; fuzzy-mapping; fuzzy set; $G$-distance function; $G^{\prime}$-distance function

\section{Introduction and preliminaries}

It is well known that the fuzzy set concept plays an important role in many scientific and engineering applications. The fuzziness appears when we need to perform, on manifold, calculations with imprecision variables. The concept of fuzzy sets was introduced initially by Zadeh [1] in 1965. Since then, Heilpern [2] introduced the concept of fuzzy mapping and proved a fixed point theorem for fuzzy contraction mappings in a metric linear space, which is a fuzzy extension of the Banach contraction principle. Subsequently several other authors [3-26] have studied existence of fixed points of fuzzy mappings satisfying some different contractive type conditions. Recently, Abbas and Turkoglu [27] also proved some useful fixed point results for fuzzy mappings, which is a fuzzy extension of some existing results. However, the aim of this paper is to prove some new fixed point theorems for fuzzy mappings under a $G$-distance function and a $G^{\prime}$-distance function in complete metric spaces. Our results extend, generalize, and improve the results of $[2,3,6-10,13,14,19$, $27,28]$.

Throughout this paper, we shall use the following notions.

Let $(X, d)$ be a metric space. A fuzzy set $A$ in $X$ is a function with domain $X$ and values in $I=[0,1]$. If $A$ is a fuzzy set and $x \in X$, then the function value $A(x)$ is called the grade of membership of $x$ in $X$. The $\alpha$-level set of $A$, denoted by $A_{\alpha}$, is defined as

$$
\begin{aligned}
& A_{\alpha}=\{x: \mu(x) \geq \alpha\} \text { if } \alpha \in(0,1], \\
& A_{0}=\{x: \mu(x)>0\},
\end{aligned}
$$

where $\bar{B}$ is the closure of the non-fuzzy set $B$.

A fuzzy set $A$ in $X$ is said to be an approximate quantity if and only if $A_{\alpha}$ is compact and convex in $X$ for each $\alpha \in(0,1]$ and $\sup _{x \in X} A(x)=1$. We denote by $W(X)$ the family of all approximate quantities in $X$. Let $A, B \in W(X)$, then $A$ is said to be more accurate $A$ than $B$, denoted by $A \subset B$, if and only if $A(x) \leq B(x)$ for each $x \in X$. 
For $A, B \in W(X), \alpha \in(0,1]$, define

$$
\begin{aligned}
& p_{\alpha}(A, B)=\inf _{x \in A_{\alpha}, y \in B_{\alpha}} d(x, y), \\
& D_{\alpha}(A, B)=H\left(A_{\alpha}, B_{\alpha}\right),
\end{aligned}
$$

where $H$ denotes the Hausdorff distance. Also

$$
\begin{aligned}
& D(A, B)=\sup _{\alpha} D_{\alpha}(A, B), \\
& p(A, B)=\sup _{\alpha} p_{\alpha}(A, B) .
\end{aligned}
$$

Let $\alpha \in[0,1]$, then the family $W_{\alpha}(X)$ is given by $\left\{A \in I^{X}: A_{\alpha}\right.$ is nonempty convex and compact . Let $X$ be an arbitrary set, $Y$ be a metric linear space. A mapping $T$ is called a fuzzy mapping if $T$ is a mapping from $X$ into $W(Y)$, that is, $T(x) \in W(Y)$ for each $x$ in $X$. Therefore, a fuzzy mapping $T$ is a fuzzy subset on $X \times Y$ with membership function $T x(y)$. A fuzzy point $x_{\alpha}$ in $X$ is called a fixed fuzzy point of the fuzzy mapping $T$ if $\left\{x_{\alpha}\right\} \subset T x$. If $\{x\} \subset T x$, then $x$ is a fixed point of $T$.

The following lemmas are needed in the sequel. Let $(X, d)$ be a metric space.

Lemma 1.1 [2] Let $x \in X$ and $A \in W(X)$. Then $\left\{x_{\alpha}\right\} \subset A$ if $p_{\alpha}(x, A)=0$.

Lemma 1.2 [2] Let $A \in W(X)$, then $p_{\alpha}(x, A) \leq d(x, y)+p_{\alpha}(y, A)$ for $x, y \in X$.

Lemma 1.3 [2] If $\left\{x_{\alpha}\right\} \subset A$, then $p_{\alpha}(x, B) \leq D_{\alpha}(A, B)$ for each $A, B \in W(X)$.

Lemma 1.4 [4] Let $(X, d)$ be a complete metric space and $T$ be a fuzzy mapping from $X$ into $W(X)$ with $x_{0} \in X$. Then there exists $x_{1} \in X$ such that $\left\{x_{1}\right\} \subset T x_{0}$.

Next, we introduce some classes of functions.

Let $\Phi$ be the set of all functions $\phi$ such that $\phi:[0,+\infty) \rightarrow[0,+\infty)$ is a continuous and nondecreasing function with $\phi(t)=0$ if and only if $t=0$.

Let $\Psi$ be the set of all function $\varphi$ such that $\varphi:[0,+\infty) \rightarrow[0,+\infty)$ is lower semicontinuous with $\varphi(t)=0$ if and only if $t=0$.

Let $\Omega$ be the set of all functions $\psi$ such that $\psi:[0,+\infty) \rightarrow[0,+\infty)$ is a nondecreasing function with $\lim _{n \rightarrow \infty} \psi^{n}(t)=0$ for all $t \in(0,+\infty)$. If $\psi \in \Omega$, then $\psi$ is called a $\Omega$-map. It is an easy matter to show that if $\psi \in \Omega$, then

(1) $\psi(t)<t$ for all $t \in(0,+\infty)$,

(2) $\psi(0)=0$.

\section{Fixed point theorems under a G-distance function}

In this section, we will show a fixed theorem for fuzzy mappings under a G-distance function in complete metric spaces. Inspired by Constantin [5], we give the following definition.

Definition 2.1 A function $g$ is said to be a G-distance function if $g:[0, \infty)^{5} \rightarrow[0, \infty)$ is a continuous function and the following properties hold: 
(i) $g$ is nondecreasing in the $2 \mathrm{nd}, 3 \mathrm{rd}, 4$ th, and 5 th variable;

(ii) if $u, v \in[0, \infty)$ are such that $u \leq g(v, v, u, u+v, 0)$ or $u \leq g(v, u, v, 0, u+v)$, then $u \leq h v$, where $0<h<1$ is a given constant;

(iii) if $u \in[0, \infty)$ is such that $u \leq g(u, 0,0, u, u)$, then $u=0$.

Next, we introduce and prove the following results which generalize the results of $[2,3$, 6-8].

Theorem 2.1 Let $(X, d)$ be a complete metric space and $g$ be a G-distance function. Suppose that $T_{1}, T_{2}: X \rightarrow W_{\alpha}(X)$ are two fuzzy mappings on $X$ satisfying the following conditions:

$$
\phi\left(D_{\alpha}\left(T_{1} x, T_{2} y\right)\right) \leq \phi(m(x, y))+L b(x, y)
$$

for all $x, y \in X$, where $L \geq 0, \phi \in \Phi$, and

$$
\begin{aligned}
& m(x, y)=g\left(d(x, y), p_{\alpha}\left(x, T_{1} x\right), p_{\alpha}\left(y, T_{2} y\right), p_{\alpha}\left(x, T_{2} y\right), p_{\alpha}\left(y, T_{1} x\right)\right), \\
& b(x, y)=\min \left\{d(x, y), p_{\alpha}\left(x, T_{1} x\right), p_{\alpha}\left(y, T_{2} y\right), p_{\alpha}\left(x, T_{2} y\right), p_{\alpha}\left(y, T_{1} x\right)\right\} .
\end{aligned}
$$

Then there exists a point $x^{*}$ in $X$ such that $\left\{x^{*}\right\} \subset T_{1} x^{*}$ and $\left\{x^{*}\right\} \subset T_{2} x^{*}$.

Proof Let $x_{0} \in X$, by Lemma 1.4 there exists $x_{1} \in X$ such that $\left\{x_{1}\right\} \in T_{1} x_{0}$, which implies that

$$
p_{\alpha}\left(x_{1}, T_{1} x_{0}\right)=0 \quad \text { for each } \alpha \in[0,1]
$$

which is possible only if $x_{1} \in\left(T_{1} x_{0}\right)_{\alpha}$. Since $\left(T_{2} x_{1}\right)_{\alpha}$ is a nonempty compact subset of $X$, there exists $x_{2} \in\left(T_{2} x_{1}\right)_{\alpha}$ such that

$$
d\left(x_{1}, x_{2}\right)=p_{\alpha}\left(x_{1}, T_{2} x_{1}\right) \leq D_{\alpha}\left(T_{1} x_{0}, T_{2} x_{1}\right) .
$$

Continuing this process, one obtains a sequence $\left\{x_{n}\right\}$ in $X$ such that $x_{2 n+1} \in\left(T_{1} x_{2 n}\right)_{\alpha}$ and $x_{2 n+2} \in\left(T_{2} x_{2 n+1}\right)_{\alpha}$ for all $n \geq 0$ and $d\left(x_{2 n+1}, x_{2 n+2}\right) \leq D_{\alpha}\left(T_{1} x_{2 n}, T_{2} x_{2 n+1}\right)$. By the nondecreasing character of $\phi,(2.1)$ and (2.2), we have

$$
\phi\left(d\left(x_{2 n+1}, x_{2 n+2}\right)\right) \leq \phi\left(D_{\alpha}\left(T_{1} x_{2 n}, T_{2} x_{2 n+1}\right)\right) \leq \phi\left(m\left(x_{2 n}, x_{2 n+1}\right)\right)+L b\left(x_{2 n}, x_{2 n+1}\right),
$$

where

$$
\begin{aligned}
m\left(x_{2 n}, x_{2 n+1}\right)= & g\left(d\left(x_{2 n}, x_{2 n+1}\right), p_{\alpha}\left(x_{2 n}, T_{1} x_{2 n}\right), p_{\alpha}\left(x_{2 n+1}, T_{2} x_{2 n+1}\right),\right. \\
& \left.p_{\alpha}\left(x_{2 n}, T_{2} x_{2 n+1}\right), p_{\alpha}\left(x_{2 n+1}, T_{1} x_{2 n}\right)\right) \\
= & g\left(d\left(x_{2 n}, x_{2 n+1}\right), d\left(x_{2 n}, x_{2 n+1}\right), d\left(x_{2 n+1}, x_{2 n+2}\right)\right. \\
& \left.d\left(x_{2 n}, x_{2 n+2}\right), d\left(x_{2 n+1}, x_{2 n+1}\right)\right) \\
\leq & g\left(d\left(x_{2 n}, x_{2 n+1}\right), d\left(x_{2 n}, x_{2 n+1}\right), d\left(x_{2 n+1}, x_{2 n+2}\right)\right. \\
& \left.d\left(x_{2 n}, x_{2 n+1}\right)+d\left(x_{2 n+1}, x_{2 n+2}\right), 0\right)
\end{aligned}
$$


and

$$
\begin{aligned}
b\left(x_{2 n}, x_{2 n+1}\right)= & \min \left\{d\left(x_{2 n}, x_{2 n+1}\right), p_{\alpha}\left(x_{2 n}, T_{1} x_{2 n}\right), p_{\alpha}\left(x_{2 n+1}, T_{2} x_{2 n+1}\right),\right. \\
& \left.p_{\alpha}\left(x_{2 n}, T_{2} x_{2 n+1}\right), p_{\alpha}\left(x_{2 n+1}, T_{1} x_{2 n}\right)\right\} \\
= & \min \left\{d\left(x_{2 n}, x_{2 n+1}\right), d\left(x_{2 n}, x_{2 n+1}\right), d\left(x_{2 n+1}, x_{2 n+2}\right),\right. \\
& \left.d\left(x_{2 n}, x_{2 n+2}\right), d\left(x_{2 n+1}, x_{2 n+1}\right)\right\} \\
= & \min \left\{d\left(x_{2 n}, x_{2 n+1}\right), d\left(x_{2 n}, x_{2 n+1}\right), d\left(x_{2 n+1}, x_{2 n+2}\right),\right. \\
& \left.d\left(x_{2 n}, x_{2 n+2}\right), 0\right\} \\
= & 0 .
\end{aligned}
$$

According to (2.3), (2.4), (2.5), the nondecreasing character of $\phi$ and $g$, and the definition of $P_{\alpha}$, we have

$$
\begin{aligned}
\phi\left(d\left(x_{2 n+1}, x_{2 n+2}\right)\right) \leq & \phi\left(m\left(x_{2 n}, x_{2 n+1}\right)\right) \\
= & \phi\left(g \left(d\left(x_{2 n}, x_{2 n+1}\right), p_{\alpha}\left(x_{2 n}, T_{1} x_{2 n}\right), p_{\alpha}\left(x_{2 n+1}, T_{2} x_{2 n+1}\right),\right.\right. \\
& \left.\left.p_{\alpha}\left(x_{2 n}, T_{2} x_{2 n+1}\right), p_{\alpha}\left(x_{2 n+1}, T_{1} x_{2 n}\right)\right)\right) \\
\leq & \phi\left(g \left(d\left(x_{2 n}, x_{2 n+1}\right), d\left(x_{2 n}, x_{2 n+1}\right), d\left(x_{2 n+1}, x_{2 n+2}\right),\right.\right. \\
& \left.\left.d\left(x_{2 n}, x_{2 n+2}\right), d\left(x_{2 n+1}, x_{2 n+1}\right)\right)\right) .
\end{aligned}
$$

By the rectangle inequality of $d$ and the above inequality, we have

$$
\begin{aligned}
\phi\left(d\left(x_{2 n+1}, x_{2 n+2}\right)\right) \leq & \left(g \left(d\left(x_{2 n}, x_{2 n+1}\right), d\left(x_{2 n}, x_{2 n+1}\right), d\left(x_{2 n+1}, x_{2 n+2}\right),\right.\right. \\
& \left.\left.d\left(x_{2 n}, x_{2 n+1}\right)+d\left(x_{2 n+1}, x_{2 n+2}\right), 0\right)\right) .
\end{aligned}
$$

From (2.6) and the nondecreasing character of $\phi$, we get

$$
\begin{gathered}
d\left(x_{2 n+1}, x_{2 n+2}\right) \leq \\
g\left(d\left(x_{2 n}, x_{2 n+1}\right), d\left(x_{2 n}, x_{2 n+1}\right), d\left(x_{2 n+1}, x_{2 n+2}\right),\right. \\
\left.d\left(x_{2 n}, x_{2 n+1}\right)+d\left(x_{2 n+1}, x_{2 n+2}\right), 0\right) .
\end{gathered}
$$

Similarly, it can be shown that

$$
\begin{aligned}
d\left(x_{2 n+2}, x_{2 n+3}\right) \leq & g\left(d\left(x_{2 n+1}, x_{2 n+2}\right), d\left(x_{2 n+1}, x_{2 n+2}\right), d\left(x_{2 n+2}, x_{2 n+3}\right),\right. \\
& \left.d\left(x_{2 n+1}, x_{2 n+2}\right)+d\left(x_{2 n+2}, x_{2 n+3}\right), 0\right) .
\end{aligned}
$$

Therefore, for all $n$, we get

$$
d\left(x_{n}, x_{n+1}\right) \leq g\left(d\left(x_{n-1}, x_{n}\right), d\left(x_{n-1}, x_{n}\right), d\left(x_{n}, x_{n+1}\right), d\left(x_{n-1}, x_{n}\right)+d\left(x_{n}, x_{n+1}\right), 0\right) .
$$

From (ii) of Definition 2.1, we can conclude that $d\left(x_{n}, x_{n+1}\right) \leq h d\left(x_{n-1}, x_{n}\right)$, where $0<h<1$. By iteration, we have $d\left(x_{n}, x_{n+1}\right) \leq h d\left(x_{n-1}, x_{n}\right) \leq \cdots \leq h^{n} d\left(x_{0}, x_{1}\right)$. Furthermore, for $m>n$,

$$
\begin{aligned}
d\left(x_{n}, x_{m}\right) & \leq d\left(x_{n}, x_{n+1}\right)+d\left(x_{n+1}, x_{n+2}\right)+\cdots+d\left(x_{m-1}, x_{m}\right) \\
& \leq\left(h^{n}+h^{n-1}+\cdots+h^{m-1}\right) d\left(x_{0}, x_{1}\right) \leq \frac{h^{n}}{1-h} d\left(x_{0}, x_{1}\right) .
\end{aligned}
$$


It follows that $\left\{x_{n}\right\}$ is a Cauchy sequence in $X$. Since $X$ is complete, there exists $x^{*}$ such that $\lim _{n \rightarrow \infty} x_{n}=x^{*}$. Next, we show that $\left\{x^{*}\right\} \subset T_{2} x^{*}, i=1,2$. Now, by Lemma 1.2,

$$
p_{\alpha}\left(x^{*}, T_{2} x^{*}\right) \leq d\left(x^{*}, x_{2 n+1}\right)+p_{\alpha}\left(x_{2 n+1}, T_{2} x^{*}\right) .
$$

From

$$
\left|p_{\alpha}\left(x^{*}, T_{2} x^{*}\right)-d\left(x^{*}, x_{2 n+1}\right)\right| \leq p_{\alpha}\left(x_{2 n+1}, T_{2} x^{*}\right) \leq D_{\alpha}\left(T_{1} x_{2 n}, T_{2} x^{*}\right)
$$

and (2.1), we have

$$
\begin{aligned}
\phi\left(\left|p_{\alpha}\left(x^{*}, T_{2} x^{*}\right)-d\left(x^{*}, x_{2 n+1}\right)\right|\right) & \leq \phi\left(D_{\alpha}\left(T_{1} x_{2 n}, T_{2} x^{*}\right)\right) \\
& \leq \phi\left(m\left(x_{2 n}, x^{*}\right)\right)+L b\left(x_{2 n}, x^{*}\right)
\end{aligned}
$$

where

$$
\begin{aligned}
m\left(x_{2 n}, x^{*}\right)= & g\left(d\left(x_{2 n}, x^{*}\right), p_{\alpha}\left(x_{2 n}, T_{1} x_{2 n}\right), p_{\alpha}\left(x^{*}, T_{2} x^{*}\right),\right. \\
& \left.p_{\alpha}\left(x_{2 n}, T_{2} x^{*}\right), p_{\alpha}\left(x^{*}, T_{1} x_{2 n}\right)\right) \\
= & g\left(d\left(x_{2 n}, x^{*}\right), d\left(x_{2 n}, x_{2 n+1}\right), p_{\alpha}\left(x^{*}, T_{2} x^{*}\right),\right. \\
& \left.p_{\alpha}\left(x_{2 n}, T_{2} x^{*}\right), d\left(x^{*}, x_{2 n+1}\right)\right)
\end{aligned}
$$

and

$$
\begin{aligned}
b\left(x_{2 n}, x^{*}\right)= & \min \left\{d\left(x_{2 n}, x^{*}\right), p_{\alpha}\left(x_{2 n}, T_{1} x_{2 n}\right), p_{\alpha}\left(x^{*}, T_{2} x^{*}\right),\right. \\
& \left.p_{\alpha}\left(x_{2 n}, T_{2} x^{*}\right), p_{\alpha}\left(x^{*}, T_{1} x_{2 n}\right)\right\} \\
= & \min \left\{d\left(x_{2 n}, x^{*}\right), d\left(x_{2 n}, x_{2 n+1}\right), p_{\alpha}\left(x^{*}, T_{2} x^{*}\right),\right. \\
& \left.p_{\alpha}\left(x_{2 n}, T_{2} x^{*}\right), d\left(x^{*}, x_{2 n+1}\right)\right\} .
\end{aligned}
$$

In (2.7), (2.8) and (2.9), let $n \rightarrow \infty$, we get

$$
\begin{aligned}
\phi\left(p_{\alpha}\left(x^{*}, T_{2} x^{*}\right)\right) \leq & \phi\left(g\left(0,0, p_{\alpha}\left(x^{*}, T_{2} x^{*}\right), p_{\alpha}\left(x^{*}, T_{2} x^{*}\right), 0\right)\right) \\
& +L \min \left\{0,0, p_{\alpha}\left(x^{*}, T_{2} x^{*}\right), p_{\alpha}\left(x^{*}, T_{2} x^{*}\right), 0\right\} \\
= & \phi\left(g\left(0,0, p_{\alpha}\left(x^{*}, T_{2} x^{*}\right), p_{\alpha}\left(x^{*}, T_{2} x^{*}\right), 0\right)\right) .
\end{aligned}
$$

Again, by the nondecreasing character of $\phi$, we have

$$
p_{\alpha}\left(x^{*}, T_{2} x^{*}\right) \leq g\left(0,0, p_{\alpha}\left(x^{*}, T_{2} x^{*}\right), p_{\alpha}\left(x^{*}, T_{2} x^{*}\right), 0\right) .
$$

Using (ii) in Definition 2.1, we can get $p_{\alpha}\left(x^{*}, T_{2} x^{*}\right)=0$. Therefore, we have $\left\{x^{*}\right\} \subset T_{2} x^{*}$. Similarly, $\left\{x^{*}\right\} \subset T_{1} x^{*}$.

Corollary 2.1 Let $(X, d)$ be a complete metric space and $g$ be a G-distance function. Suppose that $T_{1}, T_{2}: X \rightarrow W_{\alpha}(X)$ are two fuzzy mappings on $X$ and the following inequality 
holds:

$$
\phi\left(D_{\alpha}\left(T_{1} x, T_{2} y\right)\right) \leq \phi(m(x, y))-\varphi(d(x, y))
$$

for all $x, y \in X$, where $L \geq 0, \phi \in \Phi, \varphi \in \Psi$, and

$$
m(x, y)=g\left(d(x, y), p_{\alpha}\left(x, T_{1} x\right), p_{\alpha}\left(y, T_{2} y\right), p_{\alpha}\left(x, T_{2} y\right), p_{\alpha}\left(y, T_{1} x\right)\right) .
$$

Then there exists a point $x^{*}$ in $X$ such that $\left\{x^{*}\right\} \subset T_{1} x^{*}$ and $\left\{x^{*}\right\} \subset T_{2} x^{*}$.

Proof Since

$$
\phi\left(D_{\alpha}\left(T_{1} x, T_{2} y\right)\right) \leq \phi(m(x, y))-\varphi(d(x, y)) \leq \phi(m(x, y))+L b(x, y)
$$

hence, by using Theorem 2.1, there exists a point $x^{*}$ in $X$ such that $\left\{x^{*}\right\} \subset T_{1} x^{*}$ and $\left\{x^{*}\right\} \subset$ $T_{2} x^{*}$.

If in Corollary 2.1 we chose $\phi(t)=t$, we can obtain the following corollary.

Corollary 2.2 Let $(X, d)$ be a complete metric space and $g$ be a G-distance function. Suppose that $T_{1}, T_{2}: X \rightarrow W_{\alpha}(X)$ are two fuzzy mappings on $X$ and the following inequality holds:

$$
D_{\alpha}\left(T_{1} x, T_{2} y\right) \leq m(x, y)-\varphi(d(x, y))
$$

for all $x, y \in X$, where $L \geq 0, \varphi \in \Psi$, and

$$
m(x, y)=g\left(d(x, y), p_{\alpha}\left(x, T_{1} x\right), p_{\alpha}\left(y, T_{2} y\right), p_{\alpha}\left(x, T_{2} y\right), p_{\alpha}\left(y, T_{1} x\right)\right) .
$$

Then there exists a point $x^{*}$ in $X$ such that $\left\{x^{*}\right\} \subset T_{1} x^{*}$ and $\left\{x^{*}\right\} \subset T_{2} x^{*}$.

Remark 2.1 By Theorem 2.1 and the nondecreasing character of $\phi$, we have

$$
\sup _{\alpha} \phi\left(D_{\alpha}\left(T_{1} x, T_{2} y\right)\right) \leq \sup _{\alpha} \phi(m(x, y))+L \sup _{\alpha} b(x, y) .
$$

Therefore,

$$
\phi\left(\sup _{\alpha} D_{\alpha}\left(T_{1} x, T_{2} y\right)\right) \leq \phi\left(\sup _{\alpha} m(x, y)\right)+L \sup _{\alpha} b(x, y) .
$$

Again, by the nondecreasing character of $\phi, g$ and the above inequalities, we have

$$
\begin{aligned}
\phi & \left(D\left(T_{1} x, T_{2} y\right)\right) \\
& \leq \phi\left(\sup _{\alpha} m(x, y)\right)+L \sup _{\alpha} b(x, y) \\
& \leq \phi\left(g\left(d(x, y), \sup _{\alpha} p_{\alpha}\left(x, T_{1} x\right), \sup _{\alpha} p_{\alpha}\left(y, T_{2} y\right), \sup _{\alpha} p_{\alpha}\left(x, T_{2} y\right), \sup _{\alpha} p_{\alpha}\left(y, T_{1} x\right)\right)\right)
\end{aligned}
$$




$$
\begin{aligned}
& +L \min \left\{d(x, y), \sup _{\alpha} p_{\alpha}\left(x, T_{1} x\right), \sup _{\alpha} p_{\alpha}\left(y, T_{2} y\right), \sup _{\alpha} p_{\alpha}\left(x, T_{2} y\right), \sup _{\alpha} p_{\alpha}\left(y, T_{1} x\right)\right\} \\
= & \phi\left(g\left(d(x, y), p\left(x, T_{1} x\right), p\left(y, T_{2} y\right), p\left(x, T_{2} y\right), p\left(y, T_{1} x\right)\right)\right) \\
& +L \min \left\{d(x, y), p\left(x, T_{1} x\right), p\left(y, T_{2} y\right), p\left(x, T_{2} y\right), p\left(y, T_{1} x\right)\right\} .
\end{aligned}
$$

Remark 2.2 In Remark 2.1, let $\phi(t)=t$, we have

$$
\begin{aligned}
D\left(T_{1} x, T_{2} y\right) \leq & g\left(d(x, y), p\left(x, T_{1} x\right), p\left(y, T_{2} y\right), p\left(x, T_{2} y\right), p\left(y, T_{1} x\right)\right) \\
& +L \min \left\{d(x, y), p\left(x, T_{1} x\right), p\left(y, T_{2} y\right), p\left(x, T_{2} y\right), p\left(y, T_{1} x\right)\right\} .
\end{aligned}
$$

From Remark 2.1 and Remark 2.2 , we can get the following corollary.

Corollary 2.3 Let $(X, d)$ be a complete metric space and $g$ be a G-distance function. Suppose that $T_{1}, T_{2}: X \rightarrow W(X)$ are two fuzzy mappings on $X$ and the following inequality holds:

$$
\begin{aligned}
\phi\left(D\left(T_{1} x, T_{2} y\right)\right) \leq & \phi\left(g\left(d(x, y), p\left(x, T_{1} x\right), p\left(y, T_{2} y\right), p\left(x, T_{2} y\right), p\left(y, T_{1} x\right)\right)\right) \\
& +L \min \left\{d(x, y), p\left(x, T_{1} x\right), p\left(y, T_{2} y\right), p\left(x, T_{2} y\right), p\left(y, T_{1} x\right)\right\}
\end{aligned}
$$

for all $x, y \in X$, where $L \geq 0$. Then there exists a point $x^{*}$ in $X$ such that $\left\{x^{*}\right\} \subset T_{1} x^{*}$ and $\left\{x^{*}\right\} \subset T_{2} x^{*}$.

If in Corollary 2.3 we chose $\phi(t)=t$, we can obtain the following corollary.

Corollary 2.4 Let $(X, d)$ be a complete metric space and $g$ be a G-distance function. Suppose that $T_{1}, T_{2}: X \rightarrow W(X)$ are two fuzzy mappings on $X$ and the following inequality holds:

$$
\begin{aligned}
D\left(T_{1} x, T_{2} y\right) \leq & g\left(d(x, y), p\left(x, T_{1} x\right), p\left(y, T_{2} y\right), p\left(x, T_{2} y\right), p\left(y, T_{1} x\right)\right) \\
& +L \min \left\{d(x, y), p\left(x, T_{1} x\right), p\left(y, T_{2} y\right), p\left(x, T_{2} y\right), p\left(y, T_{1} x\right)\right\}
\end{aligned}
$$

for all $x, y \in X$, where $L \geq 0$. Then there exists a point $x^{*}$ in $X$ such that $\left\{x^{*}\right\} \subset T_{1} x^{*}$ and $\left\{x^{*}\right\} \subset T_{2} x^{*}$.

If in Corollary 2.4 we chose $L=0$, then we can obtain the following corollary.

Corollary 2.5 (Rashwan and Ahmed [6], Theorem 3.1) Let $(X, d)$ be a complete metric space and $g$ be a G-distance function. Suppose that $T_{1}, T_{2}: X \rightarrow W(X)$ are two fuzzy mappings on $X$ and the following inequality holds:

$$
D\left(T_{1} x, T_{2} y\right) \leq g\left(d(x, y), p\left(x, T_{1} x\right), p\left(y, T_{2} y\right), p\left(x, T_{2} y\right), p\left(y, T_{1} x\right)\right)
$$

for all $x, y \in X$. Then there exists a point $x^{*}$ in $X$ such that $\left\{x^{*}\right\} \subset T_{1} x^{*}$ and $\left\{x^{*}\right\} \subset T_{2} x^{*}$.

Corollary 2.6 (Park and Jeong [7], Theorem 3.1) Let $(X, d)$ be a complete metric space and $g$ be a G-distance function. Suppose that $T_{1}, T_{2}: X \rightarrow W(X)$ are two fuzzy mappings on $X$ 
and the following inequality holds:

$$
D\left(T_{1} x, T_{2} y\right) \leq \beta \max \left\{d(x, y), p\left(x, T_{1} x\right), p\left(y, T_{2} y\right), \frac{p\left(x, T_{2} y\right)+p\left(y, T_{1} x\right)}{2}\right\}
$$

for all $x, y \in X$ and $\beta \in[0,1)$. Then there exists a point $x^{*}$ in $X$ such that $\left\{x^{*}\right\} \subset T_{1} x^{*}$ and $\left\{x^{*}\right\} \subset T_{2} x^{*}$.

Proof We can consider the function $g:[0, \infty)^{5} \rightarrow[0, \infty)$ defined by

$$
g\left(x_{1}, x_{2}, x_{3}, x_{4}, x_{5}\right)=\beta \max \left\{x_{1}, x_{2}, x_{3}, \frac{x_{4}+x_{5}}{2}\right\} .
$$

Since $g$ is a G-distance function, hence, by Corollary 2.5, we can obtain Corollary 2.6.

Remark 2.3 (1) From Corollary 2.5, we can get Theorems 3.2 and 3.4 in Park and Jeong [7]; Theorem 3.2 in Arora and Sharma [8]; Corollaries 3.5 and 3.6 in Rashwan and Ahmed [6].

(2) From Corollary 2.6, we can obtain Theorem 3.1 in Estruch and Vidal [3] and Theorem 3.1 in Heilpern [2].

\section{Fixed point theorems under a $G^{\prime}$-distance function}

In this section, we will show some fixed theorems for fuzzy mappings under a $G^{\prime}$-distance function in complete metric spaces. However, our results extend and improve some existing results. Inspired by Sedghi et al. [12], we give the following definition.

Definition 3.1 A function $g$ is said to be a $G^{\prime}$-distance function if $g:[0, \infty)^{5} \rightarrow[0, \infty)$ is a continuous function and the following properties hold:

(i) $g$ is increasing in each co-ordinate variable;

(ii) $g(t, t, t, a t, b t) \leq t$ for every $t \in[0, \infty)$, where $a+b=2$.

Firstly, we prove a fixed point theorem about ' $D_{\alpha}(A, B)$ ' under a $G$ '-distance function. The results extend and improve many well-known results obtained by [14, 27]. Now, we establish and prove the following fixed point theorem.

Theorem 3.1 Let $(X, d)$ be a complete metric space and $g$ be a $G^{\prime}$-distance function. Suppose that $T_{1}, T_{2}: X \rightarrow W_{\alpha}(X)$ are two fuzzy mappings on $X$ satisfying the following conditions:

$$
D_{\alpha}\left(T_{1} x, T_{2} y\right) \leq \psi(m(x, y))+L \varphi(b(x, y))
$$

for all $x, y \in X$, where $L \geq 0, \psi \in \Omega, \varphi \in \Psi$, and

$$
\begin{aligned}
& m(x, y)=g\left(d(x, y), p_{\alpha}\left(x, T_{1} x\right), p_{\alpha}\left(y, T_{2} y\right), p_{\alpha}\left(x, T_{2} y\right), p_{\alpha}\left(y, T_{1} x\right)\right), \\
& b(x, y)=\min \left\{p_{\alpha}\left(x, T_{1} x\right), p_{\alpha}\left(y, T_{2} y\right), p_{\alpha}\left(x, T_{2} y\right), p_{\alpha}\left(y, T_{1} x\right)\right\} .
\end{aligned}
$$

Then there exists a point $x^{*}$ in $X$ such that $\left\{x^{*}\right\} \subset T_{1} x^{*}$ and $\left\{x^{*}\right\} \subset T_{2} x^{*}$. 
Proof Let $x_{0} \in X$, by Lemma 1.4 there exists $x_{1} \in X$ such that $\left\{x_{1}\right\} \in T_{1} x_{0}$, which implies that

$$
p_{\alpha}\left(x_{1}, T_{1} x_{0}\right)=0 \quad \text { for each } \alpha \in[0,1]
$$

which is possible only if $x_{1} \in\left(T_{1} x_{0}\right)_{\alpha}$. Since $\left(T_{2} x_{1}\right)_{\alpha}$ is a nonempty compact subset of $X$, there exists $x_{2} \in\left(T_{2} x_{1}\right)_{\alpha}$ such that

$$
d\left(x_{1}, x_{2}\right)=p_{\alpha}\left(x_{1}, T_{2} x_{1}\right) \leq D_{\alpha}\left(T_{1} x_{0}, T_{2} x_{1}\right) .
$$

Continuing this process, for all $n \geq 0$, one obtains a sequence $\left\{x_{n}\right\}$ in $X$ such that $x_{2 n+1} \in$ $\left(T_{1} x_{2 n}\right)_{\alpha}$ and $x_{2 n+2} \in\left(T_{2} x_{2 n+1}\right)_{\alpha}$. Hence, we have $d\left(x_{2 n+1}, x_{2 n+2}\right) \leq D_{\alpha}\left(T_{1} x_{2 n}, T_{2} x_{2 n+1}\right)$. By (3.1) and (3.2), we have

$$
d\left(x_{2 n+1}, x_{2 n+2}\right) \leq D_{\alpha}\left(T_{1} x_{2 n}, T_{2} x_{2 n+1}\right) \leq \psi\left(m\left(x_{2 n}, x_{2 n+1}\right)\right)+L \varphi\left(b\left(x_{2 n}, x_{2 n+1}\right)\right),
$$

where

$$
\begin{aligned}
m\left(x_{2 n}, x_{2 n+1}\right)= & g\left(d\left(x_{2 n}, x_{2 n+1}\right), p_{\alpha}\left(x_{2 n}, T_{1} x_{2 n}\right), p_{\alpha}\left(x_{2 n+1}, T_{2} x_{2 n+1}\right),\right. \\
& \left.p_{\alpha}\left(x_{2 n}, T_{2} x_{2 n+1}\right), p_{\alpha}\left(x_{2 n+1}, T_{1} x_{2 n}\right)\right) \\
= & g\left(d\left(x_{2 n}, x_{2 n+1}\right), d\left(x_{2 n}, x_{2 n+1}\right), d\left(x_{2 n+1}, x_{2 n+2}\right),\right. \\
& \left.d\left(x_{2 n}, x_{2 n+2}\right), d\left(x_{2 n+1}, x_{2 n+1}\right)\right) \\
\leq & g\left(d\left(x_{2 n}, x_{2 n+1}\right), d\left(x_{2 n}, x_{2 n+1}\right), d\left(x_{2 n+1}, x_{2 n+2}\right),\right. \\
& \left.d\left(x_{2 n}, x_{2 n+1}\right)+d\left(x_{2 n+1}, x_{2 n+2}\right), 0\right)
\end{aligned}
$$

and

$$
\begin{aligned}
b\left(x_{2 n}, x_{2 n+1}\right)= & \min \left\{p_{\alpha}\left(x_{2 n}, T_{1} x_{2 n}\right), p_{\alpha}\left(x_{2 n+1}, T_{2} x_{2 n+1}\right),\right. \\
& \left.p_{\alpha}\left(x_{2 n}, T_{2} x_{2 n+1}\right), p_{\alpha}\left(x_{2 n+1}, T_{1} x_{2 n}\right)\right\} \\
= & \min \left\{d\left(x_{2 n}, x_{2 n+1}\right), d\left(x_{2 n+1}, x_{2 n+2}\right),\right. \\
& \left.d\left(x_{2 n}, x_{2 n+2}\right), d\left(x_{2 n+1}, x_{2 n+1}\right)\right\} \\
= & \min \left\{d\left(x_{2 n}, x_{2 n+1}\right), d\left(x_{2 n+1}, x_{2 n+2}\right), d\left(x_{2 n}, x_{2 n+2}\right), 0\right\} \\
= & 0 .
\end{aligned}
$$

Now, we prove that $d\left(x_{2 n+1}, x_{2 n+2}\right) \leq d\left(x_{2 n}, x_{2 n+1}\right)$. If $d\left(x_{2 n+1}, x_{2 n+2}\right)>d\left(x_{2 n}, x_{2 n+1}\right)$, then

$$
\begin{aligned}
m\left(x_{2 n+1}, x_{2 n+2}\right) \leq & g\left(d\left(x_{2 n}, x_{2 n+1}\right), d\left(x_{2 n}, x_{2 n+1}\right), d\left(x_{2 n+1}, x_{2 n+2}\right),\right. \\
& \left.d\left(x_{2 n}, x_{2 n+1}\right)+d\left(x_{2 n+1}, x_{2 n+2}\right), 0\right) \\
\leq & g\left(d\left(x_{2 n+1}, x_{2 n+2}\right), d\left(x_{2 n+1}, x_{2 n+2}\right), d\left(x_{2 n+1}, x_{2 n+2}\right),\right. \\
& \left.2 d\left(x_{2 n+1}, x_{2 n+2}\right), 0 \times d\left(x_{2 n+1}, x_{2 n+2}\right)\right) .
\end{aligned}
$$


Since $g$ is a $G^{\prime}$-distance function, by (ii) of Definition 3.1 we can conclude that

$$
\begin{aligned}
d\left(x_{2 n+1}, x_{2 n+2}\right) \leq & \psi\left(g \left(d\left(x_{2 n+1}, x_{2 n+2}\right), d\left(x_{2 n+1}, x_{2 n+2}\right), d\left(x_{2 n+1}, x_{2 n+2}\right),\right.\right. \\
& \left.\left.2 d\left(x_{2 n+1}, x_{2 n+2}\right), 0 \times d\left(x_{2 n+1}, x_{2 n+2}\right)\right)\right) \\
\leq & \psi\left(d\left(x_{2 n+1}, x_{2 n+2}\right)\right) \\
< & d\left(x_{2 n+1}, x_{2 n+2}\right),
\end{aligned}
$$

which is a contraction. Hence, we have $d\left(x_{2 n+1}, x_{2 n+2}\right) \leq d\left(x_{2 n}, x_{2 n+1}\right)$. By (3.3) and the nondecreasing character of $\psi$, we have $d\left(x_{2 n+1}, x_{2 n+2}\right) \leq \psi\left(d\left(x_{2 n+1}, x_{2 n+2}\right)\right) \leq \psi\left(d\left(x_{2 n}, x_{2 n+1}\right)\right)$. Similarly, it can be shown that

$$
d\left(x_{2 n+2}, x_{2 n+3}\right) \leq \psi\left(d\left(x_{2 n+1}, x_{2 n+2}\right)\right) .
$$

Therefore, for all $n$, we can conclude that $d\left(x_{n}, x_{n+1}\right) \leq \psi\left(d\left(x_{n-1}, x_{n}\right)\right)$. Therefore, for positive integers $m, n(n>m)$, we get

$$
\begin{aligned}
d\left(x_{m}, x_{n}\right) & \leq d\left(x_{m}, x_{m+1}\right)+\cdots+d\left(x_{n-1}, x_{n}\right) \\
& <\psi^{m}\left(d\left(x_{0}, x_{1}\right)\right)+\cdots+\psi^{n-1}\left(d\left(x_{0}, x_{1}\right)\right) \\
& =\sum_{k=m}^{n-1} \psi^{n}\left(d\left(x_{0}, x_{1}\right)\right) \leq \sum_{k=1}^{\infty} \psi^{n}\left(d\left(x_{0}, x_{1}\right)\right) .
\end{aligned}
$$

By virtue of the condition $\sum_{k=1}^{\infty} \psi^{n}(t)<\infty$ for each $t>0$, from (3.4) we can conclude that $\left\{x_{n}\right\}$ is a Cauchy sequence. Since $X$ is complete, there exists $x^{*}$ such that $x_{n} \rightarrow x^{*} \in X$. Next, we show that $\left\{x^{*}\right\} \subset T_{2} x^{*}$. Now, by Lemma 1.2 we have

$$
\begin{aligned}
p_{\alpha}\left(x^{*}, T_{2} x^{*}\right) & \leq d\left(x^{*}, x_{2 n+1}\right)+p_{\alpha}\left(x_{2 n+1}, T_{2} x^{*}\right) \\
& \leq d\left(x^{*}, x_{2 n+1}\right)+D_{\alpha}\left(T_{1} x_{2 n}, T_{2} x^{*}\right) \\
& \leq d\left(x^{*}, x_{2 n+1}\right)+\psi\left(m\left(x_{2 n}, x^{*}\right)\right)+L \varphi\left(b\left(x_{2 n}, x^{*}\right)\right),
\end{aligned}
$$

where

$$
\begin{aligned}
& m\left(x_{2 n}, x^{*}\right) \leq g\left(d\left(x_{2 n}, x^{*}\right), d\left(x_{2 n}, x_{2 n+1}\right), p_{\alpha}\left(x^{*}, T_{2} x^{*}\right), p_{\alpha}\left(x_{2} n, T_{2} x^{*}\right), d\left(x^{*}, x_{2 n+1}\right)\right), \\
& b\left(x_{2 n}, x^{*}\right)=\min \left\{d\left(x_{2 n}, x_{2 n+1}\right), p_{\alpha}\left(x^{*}, T_{2} x^{*}\right), p_{\alpha}\left(x_{2} n, T_{2} x^{*}\right), d\left(x^{*}, x_{2 n+1}\right)\right\} .
\end{aligned}
$$

From (3.5) and (3.6) and the properties of $\psi$, let $n \rightarrow \infty$, we can get

$$
\begin{aligned}
p_{\alpha}\left(x^{*}, T_{2} x^{*}\right) \leq & 0+\psi\left(g\left(0,0, p_{\alpha}\left(x^{*}, T_{2} x^{*}\right), p_{\alpha}\left(x^{*}, T_{2} x^{*}\right), 0\right)\right)+L \varphi(0) \\
\leq & \psi\left(g \left(p_{\alpha}\left(x^{*}, T_{2} x^{*}\right), p_{\alpha}\left(x^{*}, T_{2} x^{*}\right), p_{\alpha}\left(x^{*}, T_{2} x^{*}\right)\right.\right. \\
& \left.\left.p_{\alpha}\left(x^{*}, T_{2} x^{*}\right), p_{\alpha}\left(x^{*}, T_{2} x^{*}\right)\right)\right) \\
\leq & \psi\left(p_{\alpha}\left(x^{*}, T_{2} x^{*}\right)\right) \\
< & p_{\alpha}\left(x^{*}, T_{2} x^{*}\right),
\end{aligned}
$$


which is a contraction. Hence, we can get $p_{\alpha}\left(x^{*}, T_{2} x^{*}\right)=0$. So, by Lemma 1.1 we have $\left\{x^{*}\right\} \subset T_{2} x^{*}$. Similarly, $\left\{x^{*}\right\} \subset T_{1} x^{*}$.

Next, we give an example to support our results.

Example 3.1 Let $X=[0,1]$ and let $d: X \times X \rightarrow[0,+\infty)$ be the Euclidean metric. Let $\alpha \in$ $\left(0, \frac{1}{2}\right)$ and suppose that $T_{1}, T_{2}: X \rightarrow I^{X}$ defined by

$$
\begin{aligned}
& T_{1}(0)(x)= \begin{cases}1 & \text { if } x=0 \\
\alpha & \text { if } x \in\left(0, \frac{1}{2}\right] \\
\frac{\alpha}{2} & \text { if } x \in\left(\frac{1}{2}, 1\right]\end{cases} \\
& T_{1}(1)(x)= \begin{cases}1 & \text { if } x=0 \\
2 \alpha & \text { if } x \in\left(0, \frac{1}{2}\right] \\
\frac{\alpha}{2} & \text { if } x \in\left(\frac{1}{2}, 1\right]\end{cases}
\end{aligned}
$$

and for any $z \in(0,1)$,

$$
T_{1}(z)(x)= \begin{cases}1 & \text { if } x=0 \\ \alpha & \text { if } x \in\left(0, \frac{1}{2}\right] \\ 0 & \text { if } x \in\left(\frac{1}{2}, 1\right]\end{cases}
$$

Also they are defined by

$$
\begin{aligned}
& T_{2}(0)(y)= \begin{cases}1 & \text { if } y=0, \\
\alpha & \text { if } y \in\left(0, \frac{1}{2}\right], \\
\frac{\alpha}{2} & \text { if } y \in\left(\frac{1}{2}, 1\right],\end{cases} \\
& T_{2}(1)(y)= \begin{cases}1 & \text { if } y=0, \\
2 \alpha & \text { if } y \in\left(0, \frac{1}{2}\right], \\
\frac{\alpha}{2} & \text { if } y \in\left(\frac{1}{2}, 1\right],\end{cases}
\end{aligned}
$$

and for any $z \in(0,1)$,

$$
T_{2}(z)(y)= \begin{cases}1 & \text { if } y=0 \\ \alpha & \text { if } y \in\left(0, \frac{1}{2}\right] \\ \frac{2 \alpha}{3} & \text { if } y \in\left(\frac{1}{2}, 1\right]\end{cases}
$$

Then

$$
\begin{aligned}
& T_{1}(0)_{1}=T_{1}(z)_{1}=T_{1}(1)_{1}=\{0\}, \\
& T_{1}(0)_{\alpha}=T_{1}(z)_{\alpha}=T_{1}(1)_{\alpha}=\left[0, \frac{1}{2}\right], \\
& T_{1}(0)_{\frac{\alpha}{2}}=T_{1}(1)_{\frac{\alpha}{2}}=[0,1], \quad T_{1}(z)_{\frac{\alpha}{2}}=\left[0, \frac{1}{2}\right]
\end{aligned}
$$

and

$$
T_{2}(0)_{1}=T_{2}(z)_{1}=T_{2}(1)_{1}=\{0\},
$$




$$
\begin{aligned}
& T_{2}(0)_{\alpha}=T_{2}(z)_{\alpha}=T_{2}(1)_{\alpha}=\left[0, \frac{1}{2}\right], \\
& T_{2}(0)_{\frac{\alpha}{2}}=T_{2}(1)_{\frac{\alpha}{2}}=T_{2}(z)_{\frac{\alpha}{2}}=[0,1] .
\end{aligned}
$$

Consequently,

$$
\begin{aligned}
& D_{1}\left(T_{1}(x), T_{2}(y)\right)=H\left(T_{1}(x)_{1}, T_{2}(y)_{1}\right)=0 \quad \text { for any } x, y \in X, \\
& D_{\alpha}\left(T_{1}(x), T_{2}(y)\right)=H\left(T_{1}(x)_{\alpha}, T_{2}(y)_{\alpha}\right)=0 \quad \text { for any } x, y \in X, \\
& D_{\frac{\alpha}{2}}\left(T_{1}(x), T_{2}(y)\right)=H\left(T_{1}(x)_{\frac{\alpha}{2}}, T_{2}(y)_{\frac{\alpha}{2}}\right)=0 \quad \text { for any } x \in\{0,1\} \text { and } y \in[0,1], \\
& D_{\frac{\alpha}{2}}\left(T_{1}(x), T_{2}(y)\right)=H\left(T_{1}(x)_{\frac{\alpha}{2}}, T_{2}(y)_{\frac{\alpha}{2}}\right)=\frac{1}{2} \quad \text { for any } x \in(0,1) \text { and } y \in[0,1] .
\end{aligned}
$$

Let $g\left(x_{1}, x_{2}, x_{3}, x_{4}, x_{5}\right)=x_{1}$ and let $k:[0, \infty) \rightarrow[0, \infty), \psi(t)=q t, q \in(0,1)$. Thus $\psi(t)<$ $t$ and $\sum_{n=1}^{\infty}(q t)^{n}<\infty . D_{\alpha}\left(T_{1}(x), T_{2}(y)\right)=0 \leq \psi(d(x, y))$ for each $x, y \in X$. Hence, all the conditions of Theorem 3.1 are satisfied. There exists a fuzzy point of fuzzy mappings $T_{1}$ and $T_{2}$. We can see by the definition of $T_{1}$ and $T_{2}$ that $\{0\}$ is a fixed point.

Corollary 3.1 (Abbas et al. [14], Theorem 3) Let $(X, d)$ be a complete metric space and $g$ be a $G^{\prime}$-distance function. Suppose that $T_{1}, T_{2}: X \rightarrow W_{\alpha}(X)$ are two fuzzy mappings on $X$ satisfying the following conditions:

$$
D_{\alpha}\left(T_{1} x, T_{2} y\right) \leq \psi(m(x, y))+L b(x, y)
$$

for all $x, y \in X$, where $L \geq 0, \psi \in \Omega$, and

$$
\begin{aligned}
& m(x, y)=\max \left\{d(x, y), p_{\alpha}\left(x, T_{1} x\right), p_{\alpha}\left(y, T_{2} y\right), \frac{p_{\alpha}\left(x, T_{2} y\right)+p_{\alpha}\left(y, T_{1} x\right)}{2}\right\} \\
& b(x, y)=\min \left\{p_{\alpha}\left(x, T_{1} x\right), p_{\alpha}\left(y, T_{2} y\right), p_{\alpha}\left(x, T_{2} y\right), p_{\alpha}\left(y, T_{1} x\right)\right\} .
\end{aligned}
$$

Then there exists a point $x^{*}$ in $X$ such that $\left\{x^{*}\right\} \subset T_{1} x^{*}$ and $\left\{x^{*}\right\} \subset T_{2} x^{*}$.

Proof We can consider the function $g:[0, \infty)^{5} \rightarrow[0, \infty)$ defined by

$$
g\left(x_{1}, x_{2}, x_{3}, x_{4}, x_{5}\right)=\max \left\{x_{1}, x_{2}, x_{3}, \frac{x_{4}+x_{5}}{2}\right\}
$$

Therefore, $g$ is a $G^{\prime}$-distance function. Hence, by Theorem 3.1 we can obtain Corollary 3.1 .

Let $T_{1}=T_{2}=T$, then we can get the following corollary.

Corollary 3.2 (Abbas and Turkoglu [27], Theorem 2.1) Let $(X, d)$ be a complete metric space and $g$ be a $G^{\prime}$-distance function. Suppose that $T: X \rightarrow W_{\alpha}(X)$ are two fuzzy mappings on $X$ satisfying the following conditions:

$$
D_{\alpha}(T x, T y) \leq \psi(m(x, y))+L b(x, y)
$$


for all $x \in X$, where $L \geq 0, \psi \in \Omega$, and

$$
\begin{aligned}
& m(x, y)=\max \left\{d(x, y), p_{\alpha}(x, T x), p_{\alpha}(y, T y), \frac{p_{\alpha}(x, T y)+p_{\alpha}(y, T x)}{2}\right\}, \\
& b(x, y)=\min \left\{p_{\alpha}(x, T x), p_{\alpha}(y, T y), p_{\alpha}(x, T y), p_{\alpha}(y, T x)\right\} .
\end{aligned}
$$

Then there exists a point $x^{*}$ in $X$ such that $\left\{x^{*}\right\} \subset T x^{*}$.

In Corollary 3.2, let $\psi(t)=\theta t$, we can get the following corollary.

Corollary 3.3 (Abbas and Turkoglu [27], Theorem 2.2) Let $(X, d)$ be a complete metric space and $g$ be $a G^{\prime}$-distance function. Suppose that $T: X \rightarrow W_{\alpha}(X)$ are two fuzzy mappings on $X$ satisfying the following conditions:

$$
D_{\alpha}(T x, T y) \leq \theta m(x, y)+L b(x, y)
$$

for all $x \in X$, where $L \geq 0, \theta \in(0,1)$, and

$$
\begin{aligned}
& m(x, y)=\max \left\{d(x, y), p_{\alpha}(x, T x), p_{\alpha}(y, T y), \frac{p_{\alpha}(x, T y)+p_{\alpha}(y, T x)}{2}\right\}, \\
& b(x, y)=\min \left\{p_{\alpha}(x, T x), p_{\alpha}(y, T y), p_{\alpha}(x, T y), p_{\alpha}(y, T x)\right\} .
\end{aligned}
$$

Then there exists a point $x^{*}$ in $X$ such that $\left\{x^{*}\right\} \subset T x^{*}$.

If in Corollary 3.3 we let $L=0$, we can obtain the following corollary.

Corollary 3.4 (Abbas and Turkoglu [27], Theorem 2.3) Let $(X, d)$ be a complete metric space and $g$ be a $G^{\prime}$-distance function. Suppose that $T: X \rightarrow W_{\alpha}(X)$ are two fuzzy mappings on $X$ satisfying the following conditions:

$$
D_{\alpha}(T x, T y) \leq \theta m(x, y)
$$

for all $x \in X$, where $L \geq 0, \theta \in(0,1)$, and

$$
m(x, y)=\max \left\{d(x, y), p_{\alpha}\left(x, T_{1} x\right), p_{\alpha}(y, T y), \frac{p_{\alpha}(x, T y)+p_{\alpha}(y, T x)}{2}\right\} .
$$

Then there exists a point $x^{*}$ in $X$ such that $\left\{x^{*}\right\} \subset T x^{*}$.

Secondly, we prove some fixed point theorems about ' $H(A, B)$ ' under a $G^{\prime}$-distance function. The results extend and improve some well-known results obtained by $[10,13]$. Now, we establish and prove the following fixed point theorems. But first, we must recall some basic notions in [10] as follows.

Throughout the rest of the paper, we shall use the following notations for a metric space $(X, d) . \mathrm{CB}(X)$ is the set of all nonempty closed bounded subsets of $X$ :

$$
\begin{aligned}
& D(A, B)=\inf \{d(a, b): a \in A, b \in B\} \quad \text { for any } A, B \subset X, \\
& H(A, B)=\max \left\{\sup _{x \in A} D(\{x\}, B), \sup _{x \in B} D(A,\{x\})\right\} \text { for any } A, B \subset X .
\end{aligned}
$$


It is clear that $H$ is a metric on $\mathrm{CB}(X)$ called the Hausdorff metric induced by $d$ [2].

For simplicity we write $D(A, x)$ instead of $D(A,\{x\})$ :

$$
\begin{aligned}
& K(X)=\left\{\mu \in I^{X}: \hat{\mu} \in \mathrm{CB}(X)\right\}, \quad \text { where } \hat{\mu}=\left\{x \in X: \mu(x)=\max _{y \in X} \mu(y)\right\}, \\
& H(A, B)=\max \left\{\sup _{x \in A} D(\{x\}, B), \sup _{x \in B} D(A,\{x\})\right\} \text { for any } A, B \subset X, \\
& \wedge: K(X) \rightarrow \mathrm{CB}(X), \quad \text { where } \wedge(\mu)=\hat{\mu} .
\end{aligned}
$$

Definition 3.2 [10] A fuzzy mapping $F$ is a fuzzy set-valued mapping of $X$ into $K(X)$. For a fuzzy mapping $F: X \rightarrow K(X)$ and a mapping $\wedge: K(X) \rightarrow \mathrm{CB}(X)$, the composition $\wedge \circ F$ will be denoted by $\hat{F}$. In other words,

$$
\hat{F}(x)=\hat{F}_{x}=\left\{y \in X: F_{x}(y)=\max _{z \in X} F_{x}(Z)\right\} .
$$

Definition 3.3 [10] A point $x^{*} \in X$ is called a fixed point of a fuzzy mapping $F: X \rightarrow K(X)$ if $F_{x^{*}}\left(x^{*}\right) \geq F_{x^{*}}(x)$ for any $x \in X$.

Lemma 3.1 [10] A point $x^{*} \in X$ is a fixed point of a fuzzy mapping $F: X \rightarrow K(X)$ iff $x^{*}$ is a fixed point of the induced mapping $\hat{F}: X \rightarrow \mathrm{CB}(X)$.

Lemma $3.2[10]$ For any points $w, a \in X, D(a, B) \leq d(a, w)+D(w, B)$.

Lemma 3.3 [11] For any points $A, B \in \mathrm{CB}(X)$ with $H(A, B)<\epsilon$, for each $a \in A$, there exists an element $b \in B$ such that $d(a, b)<\epsilon$.

Now, we present and prove our results.

Theorem 3.2 Let $(X, d)$ be a complete metric space. Let $F, G: X \rightarrow K(X)$ be two fuzzy mappings and $\hat{F}, \hat{G}: X \rightarrow \mathrm{CB}(X)$ be mappings induced by $F, G$ according to (3.7). Let $\psi \in \Omega$ and $g$ be $a G^{\prime}$-distance function. Suppose that for any $x, y(x \neq y) \in X$, the following holds:

$$
H(\hat{F} x, \hat{G} y)<\psi(M(x, y)),
$$

where

$$
M(x, y)=g(d(x, y), D(x, \hat{F} x), D(y, \hat{G} y), D(x, \hat{G} y), D(y, \hat{F} x)) .
$$

Then $F$ and $G$ have a common fixed point.

Proof Let $x_{0}$ be a point in $X$. Since $\hat{F} x_{0}$ is nonempty, there exists a point $x_{1} \in \hat{F} x_{0}$. Let

$$
\epsilon=\psi\left(M\left(x_{0}, x_{1}\right)\right) .
$$

Then, by inequalities (3.8) and (3.9), we have $H\left(\hat{F} x_{0}, \hat{G} x_{1}\right)<\epsilon$. Now, using Lemma 3.3 and the properties of $\psi$, we obtain $x_{2} \in X$ such that $x_{2} \in \hat{G} x_{1}$ and

$$
d\left(x_{1}, x_{2}\right)<\epsilon=\psi\left(M\left(x_{0}, x_{1}\right)\right),
$$


where

$$
\begin{aligned}
M\left(x_{0}, x_{1}\right) & =g\left(d\left(x_{0}, x_{1}\right), D\left(x_{0}, \hat{F} x_{0}\right), D\left(x_{1}, \hat{G} x_{1}\right), D\left(x_{0}, \hat{G} x_{1}\right), D\left(x_{1}, \hat{F} x_{0}\right)\right) \\
& \leq g\left(d\left(x_{0}, x_{1}\right), d\left(x_{0}, x_{1}\right), d\left(x_{1}, x_{2}\right), d\left(x_{0}, x_{2}\right), d\left(x_{1}, x_{1}\right)\right) \\
& \leq g\left(d\left(x_{0}, x_{1}\right), d\left(x_{0}, x_{1}\right), d\left(x_{1}, x_{2}\right), d\left(x_{0}, x_{1}\right)+d\left(x_{1}, x_{2}\right), 0\right) .
\end{aligned}
$$

Now, we prove that $d\left(x_{1}, x_{2}\right) \leq d\left(x_{0}, x_{1}\right)$. If $d\left(x_{1}, x_{2}\right)>d\left(x_{0}, x_{1}\right)$, by (3.10) we get

$$
M\left(x_{0}, x_{1}\right) \leq g\left(d\left(x_{1}, x_{2}\right), d\left(x_{1}, x_{2}\right), d\left(x_{1}, x_{2}\right), 2 d\left(x_{1}, x_{2}\right), 0\right) \leq d\left(x_{1}, x_{2}\right) .
$$

Hence,

$$
d\left(x_{1}, x_{2}\right)<\psi\left(d\left(x_{1}, x_{2}\right)\right)<d\left(x_{1}, x_{2}\right)
$$

which is a contraction. Therefore,

$$
d\left(x_{1}, x_{2}\right) \leq d\left(x_{0}, x_{1}\right) .
$$

Thus by inequalities (3.10), (3.11) and (3.12), we have $d\left(x_{1}, x_{2}\right)<\psi\left(d\left(x_{0}, x_{1}\right)\right)$. Continuing in the fashion, we produce a sequence $\left\{x_{n}\right\}$ of points of $X$ such that for all $n \geq 1$,

$$
x_{2 n-1} \in \hat{F} x_{2 n-2}, \quad x_{2 n} \in \hat{G} x_{2 n-1}
$$

and

$$
\begin{aligned}
& d\left(x_{2 n}, x_{2 n+1}\right)<\psi\left(d\left(x_{2 n-1}, x_{2 n}\right)\right), \\
& d\left(x_{2 n-1}, x_{2 n}\right)<\psi\left(d\left(x_{2 n-2}, x_{2 n-1}\right)\right) .
\end{aligned}
$$

Consequently,

$$
d\left(x_{n}, x_{n+1}\right)<\psi\left(d\left(x_{n-1}, x_{n}\right)\right) \leq \cdots \leq \psi^{n}\left(d\left(x_{0}, x_{1}\right)\right)
$$

for all $n \geq 1$. Therefore, for positive integers $m, n(n>m)$, we get

$$
\begin{aligned}
d\left(x_{m}, x_{n}\right) & \leq d\left(x_{m}, x_{m+1}\right)+\cdots+d\left(x_{n-1}, x_{n}\right) \\
& <\psi^{m}\left(d\left(x_{0}, x_{1}\right)\right)+\cdots+\psi^{n-1}\left(d\left(x_{0}, x_{1}\right)\right) \\
& =\sum_{k=m}^{n-1} \psi^{n}\left(d\left(x_{0}, x_{1}\right)\right) \leq \sum_{k=1}^{\infty} \psi^{n}\left(d\left(x_{0}, x_{1}\right)\right) .
\end{aligned}
$$

By virtue of the condition $\sum_{k=1}^{\infty} \psi^{n}(t)<\infty$ for each $t>0$, from (3.13), we can conclude that $\left\{x_{n}\right\}$ is a Cauchy sequence. Let $x_{n} \rightarrow u \in X$. Using Lemma 3.2, we have

$$
\begin{aligned}
D(u, \hat{G} u) & \leq d\left(u, x_{2 n-1}\right)+D\left(x_{2 n-1}, \hat{G} u\right) \leq d\left(u, x_{2 n-1}\right)+H\left(\hat{F} x_{2 n-2}, \hat{G} u\right) \\
& <d\left(u, x_{2 n-1}\right)+\psi\left(M\left(x_{2 n-2}, u\right)\right)
\end{aligned}
$$




$$
\begin{aligned}
= & d\left(u, x_{2 n-1}\right)+\psi\left(g \left(d\left(x_{2 n-2}, u\right), D\left(x_{2 n-2}, \hat{F} x_{2 n-2}\right),\right.\right. \\
& \left.\left.D(u, \hat{G} u), D\left(x_{2 n-2}, \hat{G} u\right), D\left(u, \hat{F} x_{2 n-2}\right)\right)\right) \\
\leq & d\left(u, x_{2 n-1}\right)+\psi\left(g \left(d\left(x_{2 n-2}, u\right), d\left(x_{2 n-2}, x_{2 n-1}\right),\right.\right. \\
& \left.\left.D(u, \hat{G} u), D\left(x_{2 n-2}, \hat{G} u\right), d\left(u, x_{2 n-1}\right)\right)\right) .
\end{aligned}
$$

In (3.14), let $n \rightarrow \infty$ and using the properties of $\psi$, we have

$$
\begin{aligned}
D(u, \hat{G} u) & \leq 0+\psi\left(g\left(0,0, D(u, \hat{G} u), D\left(x_{2 n-2}, \hat{G} u\right), 0\right)\right) \\
& \leq \psi(g(D(u, \hat{G} u), D(u, \hat{G} u), D(u, \hat{G} u), D(u, \hat{G} u), D(u, \hat{G} u))) .
\end{aligned}
$$

From (3.15) and (ii) of Definition 3.1, we have $D(u, \hat{G} u) \leq \psi(D(u, \hat{G} u))<D(u, \hat{G} u)$, which is a contraction and it follows from closedness of $\hat{G}$ that $u \in \hat{G} u$. Now, by Lemma 3.1, we insure that $u$ is a common fixed point of $F$ and $G$.

Corollary 3.5 (Kamran [13], Theorem 2.5) Let $(X, d)$ be a complete metric space. Let F, $G$ : $X \rightarrow K(X)$ be two fuzzy mappings and $\hat{F}, \hat{G}: X \rightarrow \mathrm{CB}(X)$ be mappings induced by $F, G$ according to (3.7). Let $\psi \in \Omega$. Suppose that for any $x, y(x \neq y) \in X$, the following holds:

$$
H(\hat{F} x, \hat{G} y)<\psi\left(\max \left\{d(x, y), D(x, \hat{F} x), D(y, \hat{G} y), \frac{D(x, \hat{G} y)+D(y, \hat{F} x)}{2}\right\}\right),
$$

then $F$ and $G$ have a common fixed point.

Proof We can consider the function $g:[0, \infty)^{5} \rightarrow[0, \infty)$ defined by

$$
g\left(x_{1}, x_{2}, x_{3}, x_{4}, x_{5}\right)=\max \left\{x_{1}, x_{2}, x_{3}, \frac{x_{4}+x_{5}}{2}\right\} .
$$

Let $x_{1}=t, x_{2}=t, x_{3}=t, x_{4}=a t, x_{5}=b t$ and $a+b=2$. Therefore,

$$
g\left(x_{1}, x_{2}, x_{3}, x_{4}, x_{5}\right)=g(t, t, t, a t, b t)=\max \left\{t, t, t, \frac{a t+b t}{2}\right\}=t \leq t .
$$

Hence, $g$ is a $G^{\prime}$-distance function. By Theorem 3.2, we can get Corollary 3.5.

From Corollary 3.5 and the nondecreasing character of $\psi$, we can get the following corollary.

Corollary 3.6 Let $(X, d)$ be a complete metric space. Let $F, G: X \rightarrow K(X)$ be two fuzzy mappings and $\hat{F}, \hat{G}: X \rightarrow \mathrm{CB}(X)$ be mappings induced by $F, G$ according to (3.7). Let $\psi \in \Omega$. Suppose that for any $x, y(x \neq y) \in X$, the following holds:

$$
H(\hat{F} x, \hat{G} y)<\psi(d(x, y)),
$$

then $F$ and $G$ have a common fixed point.

Next, we give a more general result as follows. 
Theorem 3.3 Let $(X, d)$ be a complete metric space. Let $F_{i}, F_{j}: X \rightarrow K(X)$ be two fuzzy mappings and $\hat{F}_{i}, \hat{F}_{j}: X \rightarrow \mathrm{CB}(X)$ be mappings induced by $F_{i}, F_{j}$ according to (3.7). Let $\psi \in \Omega$ and $g$ be $a G^{\prime}$-distance function. Suppose that for any $x, y(x \neq y) \in X$, the following holds:

$$
H\left(\hat{F}_{i} x, \hat{F}_{j} y\right)<\psi(M(x, y))
$$

where

$$
M(x, y)=g\left(d(x, y), D\left(x, \hat{F}_{i} x\right), D\left(y, \hat{F}_{j} y\right), D\left(x, \hat{F}_{j} y\right), D\left(y, \hat{F}_{i} x\right)\right) .
$$

Then $\left\{F_{n}\right\}$ has a common fixed point.

Proof Let $x_{0}$ be a point in $X$. Since $\hat{F}_{1} x_{0}$ is nonempty, there exists a point $x_{1} \in \hat{F}_{1} x_{0}$. Let

$$
\epsilon=\psi\left(M\left(x_{0}, x_{1}\right)\right) .
$$

Then by inequality (3.16), we have $H\left(\hat{F}_{1} x_{0}, \hat{F}_{2} x_{1}\right)<\epsilon$. Now, using Lemma 3.3 and the properties of $\psi$, we obtain $x_{2} \in X$ such that $x_{2} \in \hat{F}_{2} x_{1}$ and

$$
d\left(x_{1}, x_{2}\right)<\epsilon=\psi\left(M\left(x_{0}, x_{1}\right)\right),
$$

where

$$
\begin{aligned}
M\left(x_{0}, x_{1}\right) & =g\left(d\left(x_{0}, x_{1}\right), D\left(x_{0}, \hat{F}_{1} x_{0}\right), D\left(x_{1}, \hat{F}_{2} x_{1}\right), D\left(x_{0}, \hat{F}_{2} x_{1}\right), D\left(x_{1}, \hat{F}_{1} x_{0}\right)\right) \\
& \leq g\left(d\left(x_{0}, x_{1}\right), d\left(x_{0}, x_{1}\right), d\left(x_{1}, x_{2}\right), d\left(x_{0}, x_{2}\right), d\left(x_{1}, x_{1}\right)\right) \\
& \leq g\left(d\left(x_{0}, x_{1}\right), d\left(x_{0}, x_{1}\right), d\left(x_{1}, x_{2}\right), d\left(x_{0}, x_{1}\right)+d\left(x_{1}, x_{2}\right), 0\right) .
\end{aligned}
$$

Now, we prove that $d\left(x_{1}, x_{2}\right) \leq d\left(x_{0}, x_{1}\right)$. If $d\left(x_{1}, x_{2}\right)>d\left(x_{0}, x_{1}\right)$, by (3.18) we get

$$
M\left(x_{0}, x_{1}\right) \leq g\left(d\left(x_{1}, x_{2}\right), d\left(x_{1}, x_{2}\right), d\left(x_{1}, x_{2}\right), 2 d\left(x_{1}, x_{2}\right), 0\right) \leq d\left(x_{1}, x_{2}\right) .
$$

Hence

$$
d\left(x_{1}, x_{2}\right)<\psi\left(d\left(x_{1}, x_{2}\right)\right)<d\left(x_{1}, x_{2}\right)
$$

which is a contraction. Therefore,

$$
d\left(x_{1}, x_{2}\right) \leq d\left(x_{0}, x_{1}\right) .
$$

Thus, by inequalities (3.18), (3.19) and (3.20), we have $d\left(x_{1}, x_{2}\right)<\psi\left(d\left(x_{0}, x_{1}\right)\right)$. Continuing in the fashion, we produce a sequence $\left\{x_{n}\right\}$ of points of $X$ such that for all $n \geq 1$,

$$
x_{n} \in \hat{F}_{n} x_{n-1}
$$


and

$$
\begin{aligned}
& d\left(x_{2 n}, x_{2 n+1}\right)<\psi\left(d\left(x_{2 n-1}, x_{2 n}\right)\right), \\
& d\left(x_{2 n-1}, x_{2 n}\right)<\psi\left(d\left(x_{2 n-2}, x_{2 n-1}\right)\right) .
\end{aligned}
$$

Consequently,

$$
d\left(x_{n}, x_{n+1}\right)<\psi\left(d\left(x_{n-1}, x_{n}\right)\right) \leq \cdots \leq \psi^{n}\left(d\left(x_{0}, x_{1}\right)\right)
$$

for all $n \geq 1$. Therefore, for positive integers $m, n(n>m)$, we get

$$
\begin{aligned}
d\left(x_{m}, x_{n}\right) & \leq d\left(x_{m}, x_{m+1}\right)+\cdots+d\left(x_{n-1}, x_{n}\right) \\
& <\psi^{m}\left(d\left(x_{0}, x_{1}\right)\right)+\cdots+\psi^{n-1}\left(d\left(x_{0}, x_{1}\right)\right) \\
& =\sum_{k=m}^{n-1} \psi^{n}\left(d\left(x_{0}, x_{1}\right)\right) \leq \sum_{k=1}^{\infty} \psi^{n}\left(d\left(x_{0}, x_{1}\right)\right) .
\end{aligned}
$$

By virtue of the condition $\sum_{k=1}^{\infty} \psi^{n}(t)<\infty$ for each $t>0$, from (3.21), we can conclude that $\left\{x_{n}\right\}$ is a Cauchy sequence. Let $x_{n} \rightarrow u \in X$. Using Lemma 3.2 we have

$$
\begin{aligned}
D\left(u, \hat{F}_{n} u\right) \leq & d\left(u, x_{m}\right)+D\left(x_{m}, \hat{F}_{n} u\right) \leq d\left(u, x_{m}\right)+H\left(\hat{F}_{m} x_{m-1}, \hat{F}_{n} u\right) \\
< & d\left(u, x_{m}\right)+\psi\left(M\left(x_{m-1}, u\right)\right) \\
= & d\left(u, x_{m}\right)+\psi\left(g \left(d\left(x_{m-1}, u\right), D\left(x_{m-1}, \hat{F}_{m} x_{m-1}\right),\right.\right. \\
& \left.\left.D\left(u, \hat{F}_{n} u\right), D\left(x_{m-1}, \hat{F}_{n} u\right), D\left(u, \hat{F}_{m} x_{m-1}\right)\right)\right) \\
\leq & d\left(u, x_{m}\right)+\psi\left(g \left(d\left(x_{m-1}, u\right), d\left(x_{m-1}, x_{m}\right),\right.\right. \\
& \left.\left.D\left(u, \hat{F}_{n} u\right), D\left(x_{m-1}, \hat{F}_{n} u\right), d\left(u, x_{m}\right)\right)\right) .
\end{aligned}
$$

In (3.22), let $n \rightarrow \infty$ and using the properties of $\psi$, we have

$$
\begin{aligned}
D(u, \hat{G} u) & \leq 0+\psi\left(g\left(0,0, D\left(u, \hat{F}_{n} u\right), D\left(x_{2 n-2}, \hat{F}_{n} u\right), 0\right)\right) \\
& \leq \psi\left(g\left(D\left(u, \hat{F}_{n} u\right), D\left(u, \hat{F}_{n} u\right), D\left(u, \hat{F}_{n} u\right), D\left(u, \hat{F}_{n} u\right), D\left(u, \hat{F}_{n} u\right)\right)\right) .
\end{aligned}
$$

From (3.23) and (ii) of Definition 3.1, we have $D\left(u, \hat{F}_{n} u\right) \leq \psi\left(D\left(u, \hat{F}_{n} u\right)\right)<D\left(u, \hat{F}_{n} u\right)$, which is a contraction and it follows from the closedness of $\hat{F}_{n}$ that $u \in \hat{F}_{n} u$ for all $n=1,2, \ldots$. Now, by Lemma 3.1 , we insure that $u$ is a common fixed point of $\left\{F_{n}\right\}$.

Corollary 3.7 (Kamran [13], Theorem 2.6) Let $(X, d)$ be a complete metric space. Let $F_{i}, F_{j}$ : $X \rightarrow K(X)$ be two fuzzy mappings and $\hat{F}_{i}, \hat{F}_{j}: X \rightarrow \mathrm{CB}(X)$ be mappings induced by $F_{i}, F_{j}$ according to (3.7). Let $\psi \in \Omega$ and $g$ be $a G^{\prime}$-distance function. Suppose that for any $x, y$ ( $x \neq$ $y) \in X$, the following holds:

$$
H\left(\hat{F}_{i} x, \hat{F}_{j} y\right)<\psi\left(\max \left\{d(x, y), D\left(x, \hat{F}_{i} x\right), D\left(y, \hat{F}_{j} y\right), \frac{D\left(x, \hat{F}_{j} y\right)+D\left(y, \hat{F}_{i} x\right)}{2}\right\}\right),
$$

then $\left\{F_{n}\right\}$ has a common fixed point. 
Proof We can consider the function $g:[0, \infty)^{5} \rightarrow[0, \infty)$ defined by

$$
g\left(x_{1}, x_{2}, x_{3}, x_{4}, x_{5}\right)=\max \left\{x_{1}, x_{2}, x_{3}, \frac{x_{4}+x_{5}}{2}\right\} .
$$

Let $x_{1}=t, x_{2}=t, x_{3}=t, x_{4}=a t, x_{5}=b t$ and $a+b=2$. Therefore,

$$
g\left(x_{1}, x_{2}, x_{3}, x_{4}, x_{5}\right)=g(t, t, t, a t, b t)=\max \left\{t, t, t, \frac{a t+b t}{2}\right\}=t \leq t .
$$

Hence, $g$ is a $G^{\prime}$-distance function. By Theorem 3.3, we can get Corollary 3.7.

From Corollary 3.7 and the nondecreasing character of $\psi$, we can get the following corollary.

Corollary 3.8 Let $(X, d)$ be a complete metric space. Let $F_{i}, F_{j}: X \rightarrow K(X)$ be two fuzzy mappings and $\hat{F}_{i}, \hat{F}_{j}: X \rightarrow \mathrm{CB}(X)$ be mappings induced by $F_{i}, F_{j}$ according to (3.7). Let $\psi \in \Omega$. Suppose that for any $x, y(x \neq y) \in X$, the following holds:

$$
H\left(\hat{F}_{i} x, \hat{F}_{j} y\right)<\psi(d(x, y)),
$$

then $\left\{F_{n}\right\}$ has a common fixed point.

\section{Application}

In this section, we mainly want to give an application using Theorem 2.1.

Theorem 4.1 Let $(X, d)$ be a complete metric linear space, and let $T_{1}, T_{2}: X \rightarrow W_{\alpha}(X)$ be two fuzzy mappings on $X$ satisfying the following conditions:

$$
\begin{aligned}
{\left[D_{\alpha}\left(T_{1} x, T_{2} y\right)\right]^{2} \leq } & \alpha_{1}[d(x, y)]^{2}+\alpha_{2} p_{\alpha}\left(x, T_{1} x\right) p_{\alpha}\left(y, T_{2} y\right)+\alpha_{3} p_{\alpha}\left(x, T_{2} y\right) p_{\alpha}\left(y, T_{1} x\right) \\
& +\alpha_{4} d(x, y) p_{\alpha}\left(x, T_{1} x\right)+\alpha_{5} d(x, y) p_{\alpha}\left(y, T_{2} y\right)
\end{aligned}
$$

where $\alpha_{i}>0(i=1,2,3,4,5), \alpha_{1}+\alpha_{2}+\alpha_{4}+\alpha_{5}<1, \alpha_{1}+\alpha_{3}<1$. Then there exists a point $x^{*}$ in $X$ such that $\left\{x^{*}\right\} \subset T_{1} x^{*}$ and $\left\{x^{*}\right\} \subset T_{2} x^{*}$.

Proof We can consider the function $g:[0, \infty)^{5} \rightarrow[0, \infty)$ defined by

$$
g\left(x_{1}, x_{2}, x_{3}, x_{4}, x_{5}\right)=\left[\alpha_{1} x_{1}^{2}+\alpha_{2} x_{2} x_{3}+\alpha_{3} x_{4} x_{5}+\alpha_{4} x_{1} x_{2}+\alpha_{5} x_{1} x_{3}\right]^{\frac{1}{2}} .
$$

Next we prove that $g$ is a G-distance function. Firstly, obviously, $g$ is nondecreasing in the 2nd, 3rd, 4th, and 5th variable. Secondly,

$$
\begin{aligned}
u & \leq g(v, u, v, 0, u+v)=\left[\alpha_{1} v^{2}+\alpha_{2} u v+\alpha_{4} u v+\alpha_{5} v^{2}\right]^{\frac{1}{2}} \\
& =\left[\left(\alpha_{1}+\alpha_{5}\right) v^{2}+\left(\alpha_{2}+\alpha_{4}\right) u v\right]^{\frac{1}{2}} .
\end{aligned}
$$

If $u \leq v$, from (4.2) we can get

$$
u^{2} \leq\left(\alpha_{1}+\alpha_{5}\right) v^{2}+\left(\alpha_{2}+\alpha_{4}\right) u v \leq\left(\alpha_{1}+\alpha_{2}+\alpha_{4}+\alpha_{5}\right) v^{2} .
$$


Hence, there exists $h=\sqrt{\alpha_{1}+\alpha_{2}+\alpha_{4}+\alpha_{5}}<1$ such that $u \leq h v$, where $0<h<1$. If $u>v$, from (4.2) we can get

$$
u^{2} \leq\left(\alpha_{1}+\alpha_{5}\right) v^{2}+\left(\alpha_{2}+\alpha_{4}\right) u v<\left(\alpha_{1}+\alpha_{2}+\alpha_{4}+\alpha_{5}\right) u^{2}<u^{2}
$$

which is a contraction. Therefore, (ii) of Definition 2.1 holds. Thirdly, since $u \leq g(u, 0,0$, $u, u)=\left[\left(\alpha_{1}+\alpha_{3}\right) u^{2}\right]^{\frac{1}{2}}=\sqrt{\alpha_{1}+\alpha_{3}} u<u$, which is a contraction. Hence, $u=0$. Therefore, Theorem 4.1 satisfies all the conditions of Theorem 2.1. Hence, there exists a point $x^{*}$ in $X$ such that $\left\{x^{*}\right\} \subset T_{1} x^{*}$ and $\left\{x^{*}\right\} \subset T_{2} x^{*}$.

Remark 4.1 In Theorem 4.1, we can conclude that for $\alpha_{i}>0(i=1,2,3,4,5), \alpha_{1}+\alpha_{2}+\alpha_{4}+$ $\alpha_{5}<1, \alpha_{1}+\alpha_{3}<1$, Theorem 2.1 improves Theorem 3.1 in [9].

\section{Competing interests}

The authors declare that they have no competing interests.

\section{Authors' contributions}

All authors contributed equally and significantly in writing this article. All authors read and approved the final manuscript.

\section{Acknowledgements}

The authors thank the editor and the referees for their valuable comments and suggestions. This research has been supported by the National Natural Science Foundation of China $(11461043,11361042$ and 11326099) and supported partly by the Provincial Natural Science Foundation of Jiangxi, China (20114BAB201003 and 20142BAB201005) and the Science and Technology Project of Educational Commission of Jiangxi Province, China (GJJ11346).

Received: 18 September 2014 Accepted: 13 February 2015 Published online: 04 March 2015

\section{References}

1. Zadeh, LA: Fuzzy sets. Inf. Control 8, 338-353 (1965)

2. Heilpern, S: Fuzzy mappings and fuzzy fixed point theorems. J. Math. Anal. Appl. 83, 566-569 (1981)

3. Estruch, VD, Vidal, A: A note on fixed points for fuzzy mappings. Rend. Ist. Mat. Univ. Trieste 32, 39-45 (2001)

4. Lee, BS, Cho, SJ: A fixed point theorem for contractive type fuzzy mappings. Fuzzy Sets Syst. 61, 309-312 (1994)

5. Constantin, A: Common fixed points of weakly commuting mappings in 2-metric spaces. Math. Jpn. 36(3), 507-514 (1991)

6. Rashwan, RA, Ahmed, MA: Common fixed point theorems for fuzzy mappings. Arch. Math. 38, $219-226$ (2002)

7. Park, JY, Jeong, JU: Fixed point theorems for fuzzy mappings. Fuzzy Sets Syst. 87, 111-116 (1997)

8. Arora, SC, Sharma, V: Fixed point theorems for fuzzy mappings. Fuzzy Sets Syst. 110, 127-130 (2000)

9. Park, JY, Jeong, JU: Common fixed points of fuzzy mappings. Fuzzy Sets Syst. 59, 231-235 (1993)

10. Abu-Donia, HM: Common fixed points theorems for fuzzy mappings in metric space under $\varphi$-contraction condition. Chaos Solitons Fractals 34, 538-543 (2007)

11. Nadler, SB Jr: Multi-valued contraction mappings. Pac. J. Math. 30, 475-488 (1969)

12. Sedghi, S, Shobe, N, Altun, I: A fixed fuzzy point theorem for fuzzy mappings in complete metric space. Math. Commun. 13, 289-294 (2008)

13. Kamran, T: Common fixed points theorems for fuzzy mappings. Chaos Solitons Fractals 38, 1378-1382 (2008)

14. Abbas, M, Damjanović, B, Lazović, R: Fuzzy common fixed point theorems for generalized contractive mappings. Appl. Math. Lett. 23, 1326-1330 (2010)

15. Azam, A, Beg, l: Common fixed points of fuzzy maps. Math. Comput. Model. 49, 1331-1336 (2009)

16. Azam, A, Arshad, M, Beg, l: Fixed points of fuzzy contractive and fuzzy locally contractive maps. Chaos Solitons Fractals 42, 2836-2841 (2009)

17. Lee, BS, Cho, SJ: A fixed point theorem for contractive type fuzzy mappings. Fuzzy Sets Syst. 61, 309-312 (1994)

18. Fang, JX: A note on fixed point theorem of Hadžić. Fuzzy Sets Syst. 48, 391-395 (1992)

19. Turkoglu, D, Rhoades, BE: A fixed fuzzy point for fuzzy mapping in complete metric space. Math. Commun. 10, 115-121 (2005)

20. Ćirić, L, Abbas, M, Damjanović, B, Saadati, R: Common fuzzy fixed point theorems in ordered metric spaces. Math. Comput. Model. 53, 1737-1741 (2011)

21. Azam, A, Arshad, M: On a pair of fuzzy $\varphi$-contractive mappings. Math. Comput. Model. 52, 207-214 (2010)

22. Azam, A, Arshad, M: A note on 'Fixed point theorems for fuzzy mapping' by P. Vijayaraju and M. Marudai. Fuzzy Sets Syst. 161, 1145-1149(2010)

23. Azam, A, Waseem, M, Rashid, M: Fixed point theorems for fuzzy contractive mappings in quasi-pseudo-metric spaces. Fixed Point Theory Appl. 2013, 27 (2013)

24. Azam, A, Rashid, M: Fuzzy coincidence theorem with applications in a function space. J. Intell. Fuzzy Syst. 27, 1775-1781 (2014)

25. Azam, A, Arshad, M: Fuzzy fixed points of contractive fuzzy mappings. J. Comput. Anal. Appl. 15(6), 1006-1014 (2013) 
26. Arshad, M, Shoaib, A: Fixed points of multivalued mappings in fuzzy metric spaces. In: Proceedings of the World Congress on Engineering, London, UK, 4-6 July 2012, vol. I (2012)

27. Abbas, M, Turkoglu, D: Fixed point theorem for generalized contractive fuzzy mapping. J. Intell. Fuzzy Syst. 26, 33-36 (2014)

28. Berinde, V: General constructive fixed point theorems for Ćirić-type almost contractions in metric spaces. Carpath. J. Math. 24(2), 10-19 (2008)

Submit your manuscript to a SpringerOpen ${ }^{\circ}$ journal and benefit from:

- Convenient online submission

- Rigorous peer review

- Immediate publication on acceptance

- Open access: articles freely available online

- High visibility within the field

Retaining the copyright to your article

Submit your next manuscript at $\boldsymbol{s p r i n g e r o p e n . c o m ~}$ 